\title{
LOS INSTRUMENTOS DE PLANEAMIENTO URBANÍSTICO EN LA LEY 388 DE 1997.
}

\author{
Luís Molina López ${ }^{1}$ \\ Grupo de Estudios Urbano-Regionales del Magdalena Medio. \\ Instituto Universitario de la Paz UNIPAZ.
}

\section{Carolina Albarracín Granados}

Dirección de Desarrollo Territorial.

Ministerio de Ambiente Vivienda y Desarrollo Territorial

Remisión artículo: 26-03-2008

Palabras Clave: Planeamiento urbanístico, ordenamiento territorial, planificación territorial, Ley 388 de 1997.

Resumen: La promulgación de la Ley de Desarrollo Territorial 388 de 1997, se convierte en un punto de inflexión en la planificación territorial colombiana. Es por tal razón que el propósito central del artículo, está encaminado hacia el análisis de la estructura general de la Ley 388 de 1997, así como de la eficacia de los diferentes instrumentos de planeamiento urbano. Para ello los autores, buscaron desde una perspectiva metodológicamente cualitativa, inducir un conocimiento reflexivo con base en la experiencia adquirida durante ocho años de trabajo en varias regiones del país en los temas relacionados con el ordenamiento del territorio. Finalmente el documento aclara interrogantes frente a la jerarquía de los componentes de los planes de ordenamiento, así como en la aplicabilidad de los instrumentos de gestión del suelo en los procesos de construcción de ciudad.

\section{Introducción.}

La promulgación de la Ley de Desarrollo Territorial 388 de 1997, se convierte en un punto de inflexión en la planificación territorial en Colombia, ya que avanza en la reglamentación de las disposiciones de la Constitución Política, en adelante C.P., de 1991, frente a aspectos tales como: la función pública del urbanismo y el papel de la propiedad como función social y ecológica, al tiempo que retoma una serie de instrumentos de gestión del suelo urbano, que aun cuando algunos ya aparecían en la Ley de reforma urbana 9 de 1989, no se habían llevado adecuadamente a la práctica, o sencillamente no se habían desarrollado en los primeros ejercicios de planificación territorial.

En este contexto, el propósito central del artículo va dirigido hacia la presentación y análisis de la estructura general de la Ley 388 de 1997, así como de la eficacia de los diferentes instrumentos de planeamiento urbano. Para ello los autores, buscaron desde una perspectiva metodológicamente cualitativa, inducir un conocimiento reflexivo (Bonilla y Rodríguez, 1997, pág.73) con base en la experiencia adquirida durante ocho años de trabajo (en la formulación, revisión y ajuste de planes de ordenamiento territorial) en varias regiones del país, conjuntamente con el análisis de los aspectos urbanos contemplados en los paneles de expertos realizados en el marco del encuentro nacional: 10 años de la Ley de Ordenamiento

\footnotetext{
${ }^{1}$ Persona de contacto: Luis Molina López, correo electrónico: luis.molina@unipaz.edu.co, pdrmolina@yahoo.com
} 
Territorial: Una lectura desde las regiones de Colombia ${ }^{2}$, buscando que no solo se presentaran apreciaciones de casos singulares, sino que se avanzara en el análisis e interpretación de la realidad socio-territorial desde la misma acción participante de sus autores en los procesos de ordenación del territorio.

Fundamentalmente el artículo presenta 3 grandes apartados; el primero, desarrolla la descripción y el análisis de la estructura general de la Ley, de los componentes de los planes de ordenamiento territorial, y de las características de las normas urbanísticas y los instrumentos que las desarrollan; el segundo, aborda la eficacia de los instrumentos de planeamiento urbano, señalando la necesidad de realizar una lectura con dos escalas fundamentales de evaluación dadas las complejidades técnico-administrativas presentadas en la implementación de la Ley, y el ultimo, desarrolla las conclusiones de los temas tratados construyendo una lectura integral de los instrumentos de planeamiento urbanístico y su aplicabilidad en el contexto colombiano.

\section{Estructura general de la Ley 388 de 1997}

Antes de realizar un balance de la eficacia de los instrumentos de planeamiento contemplados en la Ley 388, se presentará un análisis general de la Ley. Para ello, el presente apartado explicara de forma detallada cada uno de los componentes de la Ley, sus principios, así como los instrumentos específicos de planificación territorial, para después desarrollar una lectura transversal de la eficacia de los mismos y su aplicación a los procesos municipales de planeamiento urbano.

\subsection{Acerca del concepto de ordenamiento territorial}

El artículo 5, capítulo II de la Ley 388, define el ordenamiento territorial municipal como:

...un conjunto de acciones político-administrativas y de planificación física concertadas, emprendidas por los municipios o distritos y áreas metropolitanas, en ejercicio de la función pública que les compete, dentro de los límites fijados por la Constitución y las leyes, en orden a disponer de instrumentos eficientes para orientar el desarrollo del territorio bajo su jurisdicción y regular la utilización, transformación y ocupación del espacio, de acuerdo con las estrategias de desarrollo socioeconómico y en armonía con el medio ambiente y las tradiciones históricas y culturales.

Se observa que la ley define un concepto de carácter local, resaltando que corresponde a un conjunto de acciones de planificación física concertadas, lo cual implica que debe existir una acción participante de los actores sociales tal como lo expresa la Constitución Política de 1991 (art. 79). Por otra parte, la definición deja ver claramente que dichas acciones no son de carácter exclusivamente urbano, aun cuando la Ley en términos generales siempre tuvo un sesgo hacia la promulgación de instrumentos de planificación y de gestión del suelo para las áreas urbanas prioritariamente.

Otro aspecto interesante de resaltar es su carácter vinculante con las estrategias de desarrollo socioeconómico, base de las teorías de planificación del desarrollo y fundamento de la planificación municipal colombiana, la cual tiene su expresión en los respectivos planes de

\footnotetext{
${ }^{2}$ Encuentro organizado por el Grupo de Estudios Urbano-Regionales del Magdalena Medio del Instituto del Universitario de la Paz UNIPAZ, el Sistema regional de Planeación Participativa del Magdalena Medio SRPPMM, La Corporación Planeación del Desarrollo Regional y la Corporación Ciencia y Cultura para el Desarrollo Regional, los días 18 y 19 de julio de 2007 en la ciudad de Barrancabermeja.
} 
desarrollo que deben formular los alcaldes electos en los primeros meses de su gobierno ${ }^{3}$. Además logra dejar explicita su apuesta por la prevalencia del interés colectivo cuando termina expresando su relación de armonía con el medio ambiente y, en especial, con las tradiciones históricas y culturales, condición que ha permitido que las comunidades campesinas y principalmente los pueblos indígenas logren avances significativos en el respeto por su cultura, tradiciones y por su relación especial con el territorio.

Finalmente, el concepto de ordenamiento no se aparta de las acepciones europeas, en cuanto lo vincula con el desarrollo del territorio y con la organización física del espacio ${ }^{4}$, permitiendo pensar la planificación territorial con una perspectiva más integral, aboliendo los viejos códigos de urbanismo como instrumento rector del planeamiento urbanístico, los que a su vez podían variar según intereses y conveniencia de los diferentes concejos municipales, aun cuando en la práctica esta consideración (incorrecta por cierto) aun tiende a prevalecer en municipios pequeños y alejados de los principales centros urbanos regionales.

\section{$2.2 \quad$ Los principios de la Ley 388}

Fundamentalmente la Ley de desarrollo territorial colombiana presenta 3 principios centrales a saber:

- La función social y ecológica de la propiedad

- La prevalencia del interés general sobre el particular

- La distribución equitativa de las cargas y los beneficios.

Adicionalmente, en sus artículos 3 y 4 , la Ley resalta como principios generales, la función pública del urbanismo y la participación democrática como ejes fundamentales en la construcción de políticas públicas ${ }^{5}$ relacionadas con el ordenamiento del territorio municipal, en tanto que estos permiten asegurar la eficacia de las políticas y propenden por el mejoramiento de la calidad de vida de los pobladores.

Al respecto conviene decir que lo más relevante de estos principios en la Ley, es el hecho que retoma dos elementos constitucionales fundamentales para el campo urbanístico: el de función social y ecológica de la propiedad, y el de la prevalencia del interés público sobre el particular (C.P, 1991, artículo 58). Además se incorporan otros como la función pública del urbanismo y la distribución equitativa de cargas y beneficios, lo que permite, según Maldonado (2004, pág. 9), concretar en diferentes escalas o ámbitos geográficos la noción de propiedad como derecho-deber.

Queda entonces definido, interpretando las disposiciones de la Constitución Política, según Maldonado, que:

La propiedad privada ha sido reconocida no solo como un derecho sino como un deber en tanto implica obligaciones, y en esa medida el ordenamiento jurídico garantiza no solo su núcleo esencial, sino su función social y ecológica, que permite conciliar los

\footnotetext{
${ }^{3}$ Los planes de desarrollo municipal son formulados por las administraciones municipales para un periodo de 4 años $y$ deben (según la Ley 152 de 1994) articularse con los planes de ordenamiento territorial, los cuales tienen una vigencia de 3 periodos administrativos, ósea 12 años.

${ }^{4}$ Para ampliar en mayor detalle, ver Carta Europea de Ordenación del Territorio (1983).

${ }^{5}$ Según Meny y Thoenig (citado en Vargas, 2001, pág.56), la política pública se entiende como "el resultado [...] de los actos y de los no actos comprometidos de una autoridad pública frente a un problema o en un sector relevante de su competencia".
} 
derechos del propietario con las necesidades de la colectividad, debidamente fundamentadas ( 2004, pág. 7).

Adicionalmente, el principio de reparto equitativo de cargas y beneficios ha generado en el planeamiento urbano colombiano, una nueva visión en la forma de construir ciudad, permitiendo que el Estado, a través de las administraciones municipales, dictaminen unas reglas de juego que permitan intervenir en el mercado de la tierra con el ánimo de garantizar que los procesos de utilización y transformación del territorio obedezcan a los pactos políticos expresados en los planes de ordenamiento, y acorde con un modelo de ciudad, construido desde la acción participante de los actores sociales.

Para finalizar este tema, conviene precisar que el proceso desarrollado en estos 10 años de vigencia de la Ley 388 , no ha sido una tarea fácil, y que su lectura, en cuanto a sus avances, debe realizarse en dos perspectivas: la primera, desde las grandes ciudades o centros regionales de primer orden a nivel nacional, en donde ha habido una mayor difusión y debate tanto de los instrumentos como de su aplicabilidad, y la segunda, desde los municipios pequeños ${ }^{6}$ en donde, pese a tener sus planes aprobados, aun existen grandes dificultades tanto en su formulación técnica, como en la comprensión de los instrumentos que brinda la Ley.

Notemos entonces, que la primera lectura deja un balance positivo, con un gran camino por recorrer, y con avances relevantes para el proceso nacional expresados en varias sentencias de la Corte Constitucional ${ }^{7}$ y representados en mejoras sustanciales en las revisiones y ajustes a los planes de ordenamiento de las principales ciudades del país; mientras que la segunda, denota la necesidad de mayor difusión y de mejoramiento de la capacidad técnicaadministrativa municipal para avanzar de forma adecuada en los propósitos centrales no solo de la Ley, sino de la Constitución Política, situación que no ha podido ser cumplida en cabalidad por la presencia de cacicazgos políticos que se rehúsan a su desaparición y a ceder sus intereses particulares frente a la reivindicación de los derechos de la colectividad.

\subsection{Los componentes de los planes de ordenamiento}

Antes de indicar los componentes de los planes de ordenamiento, se debe resaltar el hecho de que la Ley 388 prevé 3 tipos de planes (artículo 9): 1) Plan de Ordenamiento Territorial, son los "elaborados y adoptados por las autoridades de los distritos y municipios con población superior a 100.000 habitantes"; 2) Planes Básicos de Ordenamiento Territorial, "elaborados y adoptados por las autoridades de los municipios con población entre 30.000 y 100.000 habitantes"; y 3) Esquemas de Ordenamiento Territorial, "elaborados y adoptados por las autoridades de los municipios con población inferior a los 30.000 habitantes". En todo caso los componentes que se tratarán a continuación son parte integral y obligatoria en cualquiera de los planes mencionados.

En términos generales, los planes de ordenamiento presentan 3 grandes componentes, el general, el urbano y el rural, cada uno de ellos contiene unos requerimientos claros y representan un nivel de planificación específico, "...un poco a la manera de cascada de planes Española, que se articulan al de gestión del suelo, de manera que dependen entre sí" (Maldonado, 2004, pág.9), y que se condensa en un solo documento denominado Plan de Ordenamiento Territorial.

\footnotetext{
${ }^{6}$ Según el censo 2005, realizado por el Departamento Administrativo Nacional de Estadística DANE, en Colombia el $72,7 \%$ de los municipios tiene poblaciones en áreas urbanas por debajo de los 10.000 habitantes, y el 54,9\% del total nacional urbano está debajo de los 5.000 .

${ }^{7}$ Para ampliar más, ver Corte Constitucional de Colombia: Sentencias de Tutela No. T/427 de 1998 y T-523 de 1994; Sentencias de constitucionalidad C-223/94 y 275 de 1996.
} 
En este sentido y acorde con el artículo 11 de la Ley, el componente general de los planes de ordenamiento "estará constituido por los objetivos, estrategias y contenidos estructurales de largo plazo"; el componente urbano "por las políticas, acciones, programas y normas para encauzar y administrar el desarrollo físico urbano; y el componente rural "por las políticas, acciones, programas y normas para orientar y garantizar la adecuada interacción entre los asentamientos rurales y la cabecera municipal" (ver figura 1).

Ahora bien, cada uno de los componentes definen claramente las intervenciones tanto estructurales como detalladas para el territorio municipal, pero se debe enfatizar el hecho que la Ley define y detalla con mayor rigurosidad los instrumentos de gestión del suelo ${ }^{8}$ para las áreas urbanas (retomadas por supuesto en el componente urbano), situación que implica un avance en el planeamiento y gestión del suelo urbano, pero que no da un tratamiento igual a las áreas rurales y pone en desventaja a los municipios con vocación rural, que como ya señalábamos antes son más del $72,7 \%$ del total nacional.

Asimismo, la estructura de la Ley, pese a ser clara, en la práctica cotidiana de los municipios pequeños se encuentra una fuerte tendencia a confundir las normas urbanísticas, contempladas en el artículo 15 de la Ley, con las normas de reglamentación de usos específicos para las áreas urbanas (componente urbano), debido a la inadecuada interpretación que hacen los técnicos de planeación municipal sobre el término urbanístico, relacionándolo directamente con lo urbano y no con lo territorial municipal en donde se involucra tanto lo rural como lo urbano, que era lo que pretendía la Ley.

Otro aspecto de confusión en la formulación de los planes y de sus componentes, y debido a la falta de preparación técnica para enfrentar el proceso, fue abordar el plan de ordenamiento al mismo estilo del plan de desarrollo dispuesto por la Ley 152 de 1994 ${ }^{9}$, presentando adicionalmente confusiones con la obligatoriedad en la utilización de las guías metodológicas que desde los entes nacionales se empezaron a formular, hasta el punto que las autoridades ambientales ${ }^{10}$ exigían para su aprobación y concertación el desarrollo procedimental de dichas guías en la formulación de los planes, elevándolas al rango de obligatorias.

\footnotetext{
${ }^{8}$ Según Maldonado (2002, pág. 7) "La gestión del suelo puede ser definida como el conjunto de intervenciones de las entidades públicas sobre el mercado de la tierra, tendientes a corregir lo que podría conducir a evoluciones socialmente inaceptables, ineficientes en materia económica y ecológicamente peligrosas, dada la naturaleza económica de la tierra y, de manera aun más simple, todas las acciones tendientes a asignar una utilización a los terrenos".

${ }^{9}$ Dicha Ley, establece la obligatoriedad, para las administraciones municipales, de realizar un plan de desarrollo (de carácter socioeconómico) que debe contener una parte estratégica y un plan de inversiones.

${ }^{10}$ Las autoridades ambientales son una instancia de concertación y consulta, contemplada en el artículo 24 de la Ley 388 , la cual debe emitir una aprobación concerniente a los asuntos exclusivamente ambientales de los planes de ordenamiento territorial. El papel de estas autoridades ambientales fue, en sus primeros años, un problema adicional que tuvieron que enfrentar los municipios para la aprobación de sus respectivos planes de ordenamiento territorial, ya que dichas autoridades, en su mayoría, tenían muy pocos profesionales preparados técnicamente para abordar el proceso de revisión de los P.O.T.
} 
Figura 1 Componentes de los planes de ordenamiento territorial.

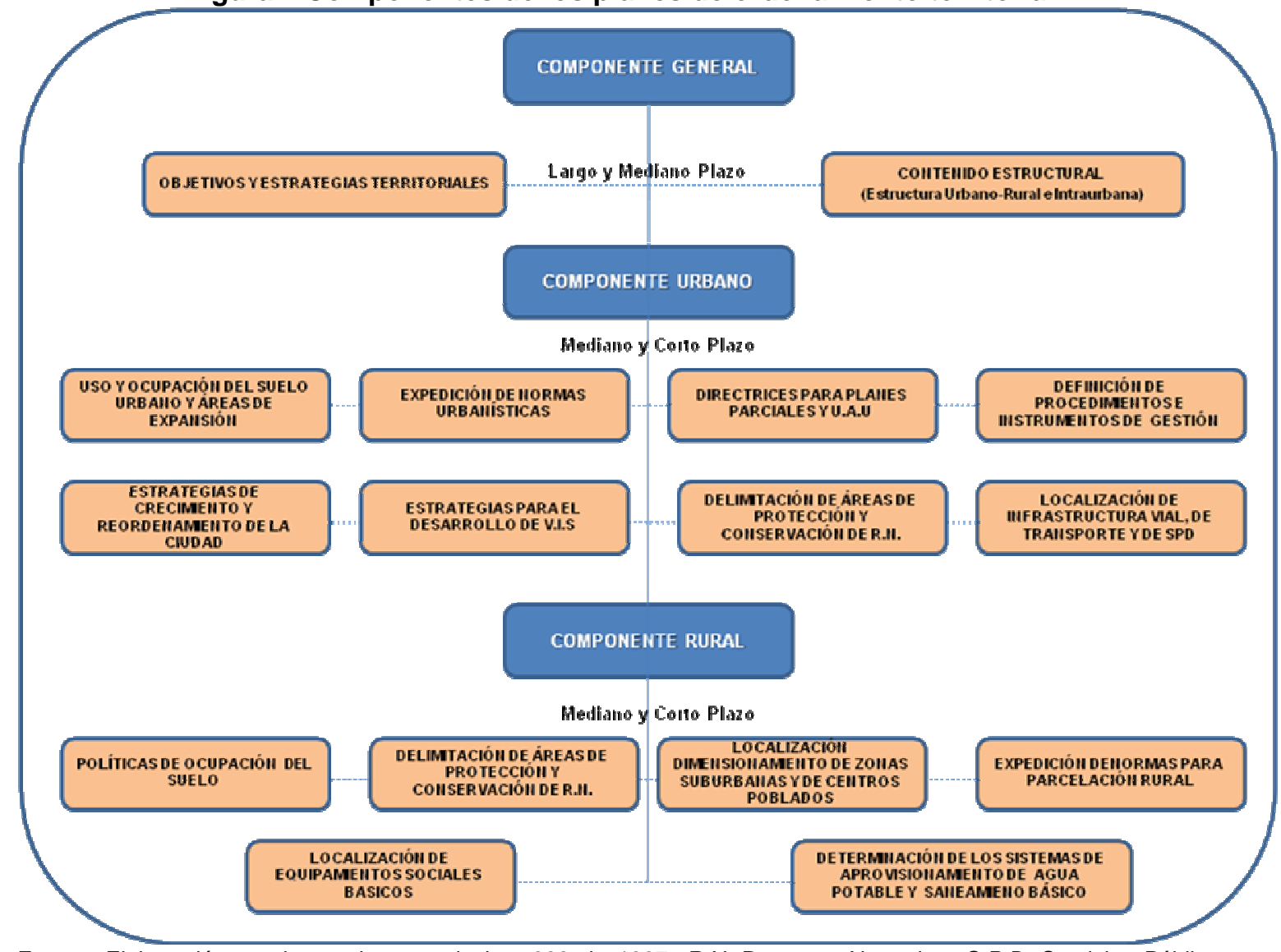

Fuente: Elaboración propia con base en la Ley 388 de 1997. R.N. Recursos Naturales. S.P.D. Servicios Públicos Domiciliarios. U.A.U. Unidades de Actuación Urbanística. V.I.S. Vivienda de Interés Social.

\section{$2.4 \quad$ Las normas urbanísticas}

Cuando la Ley 388 presenta el termino de normas urbanísticas, parece referirse a la conocida normativa de usos del suelo urbano, pero en su espíritu lo que intenta reflejar es una jerarquía de intervención territorial, que a futuro será fundamental en el seguimiento y evaluación de los planes, ya que no permitirá que estos pierdan su carácter de largo plazo, ni que sean fácilmente manipulables por aquellas administraciones que no participaron en su formulación.

En este sentido la Ley, en su artículo 15, determina que las normas urbanísticas son las que "...regulan el uso, la ocupación y el aprovechamiento del suelo y definen la naturaleza y las consecuencias de las actuaciones urbanísticas indispensables para la administración de estos procesos". Asimismo, establece su jerarquía de la siguiente manera:

1) Normas urbanísticas estructurales: "son las que aseguran la consecución de los objetivos y estrategias adoptadas en el componente general del Plan y en las políticas y estrategias de mediano plazo del componente urbano". Estas normas prevalecen sobre las demás y solo podrá emprenderse su modificación con la revisión general del plan, o por el alcalde con base en estudios técnicamente sustentados (cursiva nuestra).

2) Normas urbanísticas generales: "Son aquellas que permiten establecer usos e intensidad de usos del suelo, así como actuaciones, tratamientos y procedimientos de parcelación, urbanización, construcción e incorporación al desarrollo de las diferentes 
zonas comprendidas dentro del perímetro urbano y suelo de expansión". Son las normas de segundo nivel y las que más se relacionan con la distribución de cargas y beneficios, contempladas en los principios de la Ley, así como las que articulan las disposiciones de la noción de propiedad como derecho-deber, ya que otorgan derechos e imponen obligaciones urbanísticas a los propietarios de terrenos y a sus constructores.

3) Normas urbanísticas complementarias: Son las "relacionadas con las actuaciones, programas y proyectos adoptados en desarrollo de las previsiones contempladas en los componentes general y urbano del Plan de Ordenamiento, y [...] todas las regulaciones que se expidan para operaciones urbanas específicas y casos excepcionales, de acuerdo con los parámetros, procedimientos y autorizaciones emanadas de las normas urbanísticas generales". Dentro de esta categoría se encuentran contemplados los planes parciales (figura fundamental en el procedimiento de reparto de cargas y beneficios).

Según Maldonado (2004, pág. 13) "las normas urbanísticas (clasificación del suelo, usos, edificabilidad) en el sistema urbanístico colombiano tienen una relación directa con la movilización de recursos ligados al desarrollo urbanístico, es decir, tienen un contenido patrimonial ligado a un sistema de reparto". En esta afirmación se hace referencia implícita también a las disposiciones establecidas en la Ley (como la recuperación de plusvalías, los bancos inmobiliarios de tierras o el derecho de preferencia) que permiten intervenir en el mercado de la tierra, algo casi impensable antes de la expedición de la Ley de desarrollo territorial.

Ahora bien, dentro de este marco de normas urbanísticas y de intenciones legislativas, debe considerarse que la ausencia de un proceso serio de capacitación en el reciente tema del ordenamiento del territorio, unido a las enquistadas prácticas alrededor de los códigos de urbanismo, como instrumento sagrado para el planeamiento urbano, fueron algunas de las causas principales por las cuales la interpretación de la Ley tuvo en sus inicios demasiadas dificultades para los municipios medianos y pequeños. Dicha situación se sigue presentando después de 10, repercutiendo seguramente, pero en menor cuantía, en graves falencias y desaciertos en su implementación y en sus procesos de revisión.

\subsection{Los instrumentos de planeamiento urbano}

Los instrumentos de planeamiento urbano contemplados en la Ley se refieren en principio a tres grandes figuras (ver figura 2): la primera, corresponde al plan de ordenamiento como tal, especialmente al desarrollo de su componente urbano; la segunda, se refiere al plan parcial, el que a su vez juega un doble papel tanto de instrumento de planeamiento como de instrumento de gestión del suelo; y el tercero, corresponde a las unidades de actuación urbanística, que al igual que el plan parcial cumple la doble función de instrumento de gestión y de planeamiento, siendo la primera su espina dorsal frente al aprovechamiento del suelo y en la definición final del reparto equitativo de cargas y beneficios, así como para la generación de suelo con fines de uso público.

El plan de ordenamiento, como instrumento de planeamiento, establece específicamente para su componente urbano, que:

...es un instrumento para la administración del desarrollo y la ocupación del espacio físico clasificado como suelo urbano y suelo de expansión urbana, que integra políticas de mediano y corto plazo, procedimientos e instrumentos de gestión y normas urbanísticas (Ley 388 de 1997, articulo 13). 
Con este instrumento se dejaran explicitas las políticas de uso y ocupación del suelo, la localización de infraestructura vial y de transporte, la delimitación de áreas para la protección y conservación de los recursos naturales, los tratamientos y actuaciones urbanísticas, las estrategias para los programas de vivienda de interés social, las estrategias de crecimiento y reordenamiento de la ciudad, las características de las unidades de actuación urbanística, las directrices para la formulación de planes parciales, la expedición de normas urbanísticas y los procedimientos e instrumentos de gestión urbana.

Por su parte, el plan parcial, es el instrumento:

...mediante el cual se desarrollan y complementan las disposiciones de los planes de ordenamiento territorial, para áreas determinadas del suelo urbano y para las áreas incluidas en el suelo de expansión urbana, además de las que deban desarrollarse mediante unidades de actuación urbanística, macroproyectos u otras operaciones urbanas especiales, de acuerdo con las autorizaciones emanadas de las normas urbanísticas generales (Ibíd., artículo 19).

El plan parcial definirá los objetivos y directrices urbanísticas (espacio público, alternativas de expansión, estímulos a los propietarios e inversionistas para el mejor aprovechamiento de los inmuebles y los programas y proyectos urbanísticos entre otros), las normas urbanísticas específicas, las características del espacio público, el trazado de vías y la adopción de instrumentos de manejo del suelo (captación de plusvalías, reparto de cargas y beneficios, evaluación financiera de las obras).

Finalmente las unidades de actuación urbanística, son:

...el área conformada por uno o varios inmuebles, explícitamente delimitada en las normas que desarrolla el Plan de Ordenamiento que debe ser urbanizada o construida como una unidad de planeamiento con el objeto de promover el uso racional del suelo, garantizar el cumplimiento de las normas urbanísticas y facilitar la dotación con cargo a sus propietarios, de la infraestructura para el transporte, los servicios públicos domiciliarios y los equipamientos colectivos mediante reparto equitativo de las cargas y beneficios (Ibíd., artículo 39) (cursiva nuestra).

Con las anteriores consideraciones se observa la integración y relación directa entre los instrumentos de planificación con los de gestión del suelo, estableciendo claramente que los primeros desarrollan y complementan las políticas, objetivos y estrategias del P.O.T. y concretizan la norma urbanística en áreas específicas del suelo urbano o de las zonas de expansión, y los segundos, permiten establecer los mecanismos para el reparto equitativo de cargas y beneficios (los aprovechamientos específicos del suelo y el cálculo de las plusvalías). Esta situación de jerarquización de planes y unidades de planeamiento a diferentes escalas territoriales (ver figura 2), que no estaban muy explicitas en la Ley, ocasionaron una confusión para muchos municipios de escala media y pequeña, hasta el punto de dejarlos, en muchas ocasiones, solamente enunciados en sus documentos pero sin claridad alguna para su posterior aplicación en el proceso de planeamiento urbano. 
Figura 2 Jerarquía de los instrumentos de planeamiento urbano.

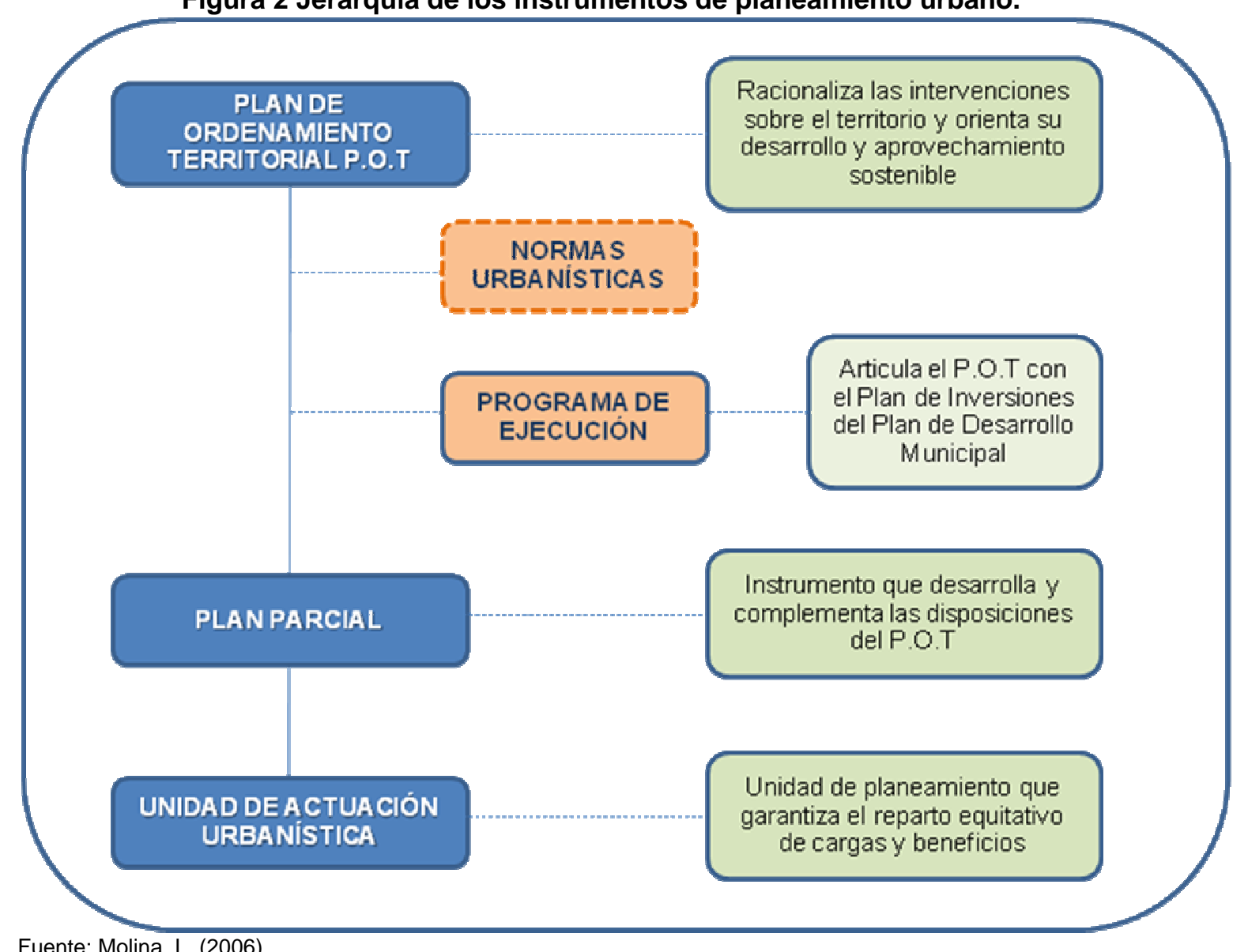

Fuente: Molina, L. (2006).

\section{La eficacia de los instrumentos de planeamiento urbano}

Como se ha expresado en otros apartes del presente documento, cuando se aborda el tema de la eficacia de los instrumentos de planeamiento urbano en el proceso de ordenamiento territorial colombiano, se deben contemplar dos escenarios básicos de análisis, ya que el nivel de articulación, difusión e implementación de los diferentes instrumentos contemplados en la Ley no han logrado el mismo grado de eficacia en todos los municipios del país.

En el primer escenario, el que corresponde a las grandes ciudades y principales centros urbanos regionales, el proceso presenta avances considerables, a pesar que aun existen dificultades tanto en su comprensión como en su implementación, dichos avances han permitido que ciudades como Bogotá desarrollen intervenciones trascendentales para el ordenamiento urbano, denominadas operaciones estratégicas. Un ejemplo claro de ello fue el Plan Zonal Centro en donde con tan solo el $17 \%$ de inversión pública se consiguieron la construcción de $330.000 \mathrm{~m}^{2}$ de espacio público, $335.000 \mathrm{~m}^{2}$ de nuevas zonas verdes, 42.000 $\mathrm{m}^{2}$ de ejes peatonales, 15,6 km de nuevas vías y 40,6 km de nuevas vías en el sistema integrado de transporte, sin contar con los $4.500 .000 \mathrm{~m}^{2}$ de nuevos desarrollos inmobiliarios ${ }^{11}$.

\footnotetext{
${ }^{11}$ Datos tomados de la Ponencia presentada del P.O.T de Bogotá ante el Congreso de la República de Colombia, el 17 de mayo de 2007, en el marco de los 10 años de la Ley 388 de 1997, sus aportes al ordenamiento urbano y a la consolidación de políticas de suelo.
} 
Asimismo, otras ciudades como Medellín aplican los planes parciales en intervenciones de renovación urbana y en la producción de nuevos desarrollos urbanísticos; muestra de ello es la meta trazada, al año 2007, por el gobierno municipal frente a la planificación de 447 hectáreas mediante la aprobación de 17 planes parciales ${ }^{12}$. En este punto vale la pena hacer una pequeña digresión, para enfatizar que en ciertos casos, la delimitación de unidades espaciales con áreas demasiado pequeñas no permite trascender del planeamiento particular (predio a predio) hacia escalas espaciales mayores en donde se obtenga una mejor visión de conjunto de los espacios estratégicos para la construcción de ciudad, situación que en principio se ha ganado legalmente con la promulgación de la Ley 388.

Con respecto al segundo escenario, la situación es muy distinta puesto que los municipios medianos y pequeños, haciendo la salvedad en algunas excepciones, no han logrado trascender hacia una visión del ordenamiento territorial como un instrumento de planificación a largo plazo, que debe ser construido como un acuerdo político a través de la acción participante de los actores sociales, y no como una simple condición de obligatoriedad frente a las disposiciones normativas que pueden modificarse a conveniencia de los intereses particulares por encima de los colectivos, o desconociendo que los planes de ordenamiento "exigen una estrecha articulación con los planes de desarrollo, pues los primeros deben establecer el marco espacial de los segundos y estos deben formular directrices para los primeros; sin embargo, en la práctica cada plan se maneja como una actuación independiente" (Massiris, 2006, pág. 129).

En la revisión empírica desarrollada en los últimos 8 años en municipios de los departamentos de Casanare, Santander, Bolívar, Cesar, Antioquia, Córdoba, Atlántico, Santander del Norte, Valle del Cauca, Meta, Risaralda y Quindío $0^{13}$, se encuentra que existen planes de ordenamiento con graves falencias tanto en su formulación como en su implementación, llegando al punto que en departamentos como Casanare y Bolívar, los documentos finales aprobados por el Concejo Municipal, no se encuentran completos o no corresponden con los que revisaron las autoridades ambientales. Situación que denota la grave ausencia de una verdadera visión del ordenamiento como proceso y como instrumento de planificación.

En cuanto a los instrumento de planeamiento urbano, es casi una regla general, que en los municipios pequeños no se apliquen (planes parciales y unidades de actuación urbanística), ya que estos solo se han limitado a utilizar, en el mejor de los casos, las normas de usos del suelo contempladas en los componentes urbanos de los respectivos planes. Por su parte los municipios de tamaño mediano han efectuado diversas aplicaciones e interpretaciones de los instrumentos según la capacidad técnica de sus profesionales o acorde con las conveniencias particulares de los promotores de vivienda sin importar su articulación con los planes de ordenamiento.

En este sentido vemos que ciudades como Barrancabermeja y Yopal $^{14}$, han hecho caso omiso a las disposiciones de sus planes de ordenamiento, ya que en la primera, se han construido

\footnotetext{
${ }^{12}$ Ibíd. P.O.T Medellín. En este caso se evidencian unidades que en promedio poseen 26,2 hectáreas, lo que puede repercutir en la pérdida de la visión integral en la planificación del conjunto urbano.

${ }^{13}$ Se hace referencia a estos departamentos, de los 32 que existen en Colombia, por dos razones fundamentales: 1) porque son regiones en donde los autores han adelantado proyectos específicos de formulación, revisión y ajuste a P.O.T., y 2) hacen parte de la información suministrada en las ponencias realizadas en el Encuentro Nacional "10 años de la Ley de Ordenamiento Territorial: Una lectura desde las regiones de Colombia".

${ }^{14}$ Barrancabermeja tiene una de las refinerías más grandes de Latinoamérica y Yopal es capital del departamento de Casanare y recibe cuantiosas inversiones producto de las regalías percibidas por la extracción de hidrocarburos. Las dos ciudades contienen más de 100.000 habitantes y presentan interesantes dinámicas en su crecimiento debido a la inversión que reciben de las regalías petroleras, por ello se toman como dos ejemplos claros de ciudades intermedias
} 
obras de infraestructura por más de 10.000.000.000 millones de pesos en sectores para los cuales es obligatorio formular con anticipación un plan parcial, o en la segunda, se han desarrollado proyectos por más de 5.000.000.000 en zonas que no habían sido declaradas de expansión urbana por el P.O.T.

Cabe concluir que los instrumentos de planeamiento urbano han logrado, en casos como Bogotá, Cali y Medellín, y en otras ciudades de relevancia urbano regional, avanzar en la construcción de territorios más incluyentes y con menores desequilibrios en la provisión de servicios sociales básicos (salud, educación, servicios públicos domiciliarios, recreación), al tiempo que han impreso una visión más integral e integradora a la hora de realizar intervenciones urbanas en beneficio de la colectividad; pero es imperante señalar que aun, después de 10 años, se está asimilando las disposiciones de la Ley 388 y las enormes ventajas de los instrumentos de planeamiento en la construcción de ciudades más incluyentes y menos segregadas ${ }^{15}$ en su espacio socio-territorial.

\section{Conclusiones}

Según Maldonado (2004, pág.8), la Ley 388 "fue expedida como una reforma a la Ley 9 de 1989, es decir, que pretendió dar continuidad al objetivo de una reforma urbana [de allí su sesgo urbano] que traduce una reivindicación del papel de la planificación urbanística en sus distintas dimensiones, articulada a la gestión del suelo o intervención en el mercado de la tierra", situación claramente descrita en la doble funcionalidad de los planes parciales y en las unidades de actuación urbanística, los cuales actúan simultáneamente como instrumento de gestión del suelo y de planeamiento urbano.

Un avance significativo en los procesos de planificación territorial en Colombia, se asocia con la superación de la escala de trabajo del predio a predio, que acontecía de forma general en el país, y avanza en la presentación y articulación de instrumentos de gestión que, conjuntamente con los de planeamiento urbano, permiten trascender la escala de lo particular hacia lo colectivo, de forma que construye una nueva lectura del territorio con mayor integralidad y propiciando una adecuada distribución de las cargas y beneficios en las actuaciones urbanas (parcelación, urbanización y edificación de inmuebles).

Tenemos en consecuencia que la promulgación de la Ley de desarrollo territorial, ha proporcionado un nuevo marco instrumental y de política pública que redefine la forma clásica de planeamiento urbanístico en Colombia. Dicha situación trae consigo la necesidad de efectuar acciones concretas y acompañamiento directo por parte del Estado, especialmente en la escala municipal, frente a la definición y cumplimiento de los derechos y deberes de los distintos actores (públicos, privados y comunitarios) que asisten a la construcción de un modelo de ciudad más incluyente y menos fragmentada. Ya que de lo contrario, los intereses particulares y la especulación con los precios de la tierra, serán las pautas que guiaran la organización físico-espacial del territorio.

Con todo lo expresado hasta ahora, podemos decir que la planificación territorial y en especial la aplicación de instrumentos de planeamiento urbano, a partir de la promulgación de la Ley

en donde los instrumentos de planeamiento urbano deberían jugar un papel preponderante dentro del desarrollo territorial municipal.

${ }^{15}$ El termino de segregación, se ha asumido en este texto con una connotación negativa desde la base de las diferencias económicas, ya que ha sido una de las formas más generalizadas del término en Latinoamérica, pero no se quiere con esto desconocer que el concepto es mucho más amplio y requiere acepciones más profundas. Para ampliar este tema en el contexto Latinoamericano ver: La segregación social del espacio en las ciudades de América Latina (Sabatini, 2003). 
388, es un tema complejo de valorar, ya que tiene matices distintos dependiendo el ámbito de aplicación desde el cual se observe. Pero se debe resaltar que desde una perspectiva más amplia, los fallos administrativos que se han dado desde el orden nacional, le otorga un fuerte marco legal y mayores elementos de sustento técnico-administrativo para que los próximos ejercicios de revisión y ajuste avancen en procesos más incluyentes y en donde se refleje una verdadera apuesta por una visión de desarrollo compartida de los municipios y sus ciudades

\section{Bibliografía.}

Bonilla, Elssy y Penélope, Sehk. Más allá del dilema de los métodos, la investigación en ciencias sociales. Bogotá: Uniandes, 1997.

Maldonado, María. El Proceso de construcción del sistema urbanístico colombiano: entre reforma urbana y ordenamiento territorial. Bogotá, 2004.

Maldonado, María. Instrumentos de gestión del suelo: algunos elementos de contexto. Bogotá, 2002.

Massiris, Ángel. Políticas latinoamericanas de ordenamiento territorial: realidad y desafíos. Tunja: Universidad Pedagógica y Tecnológica de Colombia, 2006.

Sabatini, Francisco. La segregación social del espacio en las ciudades de América Latina. Documentos del Instituto de Estudios Urbanos de la Universidad de Chile, 2003, Serie Azul No 35.

Vargas, Alejo. Notas sobre el estado y las políticas públicas. Bogotá: Almudena, 2001.

Legislación colombiana consultada

República de Colombia, Congreso de la república. Ley 152 de 15 de julio de 1994, por la cual se establece la Ley orgánica del plan de desarrollo.

República de Colombia, Congreso de la república. Ley 388 de 18 de julio de 1997, por la cual se modifica la Ley 9 de 1989 y se dictan otras disposiciones.

República de Colombia, Ministerio de Ambiente Vivienda y Desarrollo Territorial. Decreto 2181 de 29 de junio de 2005, por la cual se reglamentan parcialmente las disposiciones relativas a planes parciales contenidas en la Ley 388 de 1997 y se dictan otras disposiciones en materia urbanística. 